\title{
Coping and co-creation: one attempt and one route to well-being
}

Tjeerd Andringa, University College, University of Groningen, The Netherlands

Florence Denham, Crisis and Security Management, University of Leiden, The Netherlands

\begin{abstract}
:
All life strives to be well, but not all life is well. In this theoretical article we systematically specify the evolutionary core cognition of well-being in general living agents and we apply that to humans. We identify two strategies for the creation and protection of the conditions required for well-being and describe the associated behavioral ontologies. One strategy, coping, is for survival and the other strategy, co-creation, is for thriving. We summarize core cognition and the ontologies in two tables with defined key terms.
\end{abstract}

Coping and co-creation correspond to two complementary ontologies of cognition that follow their own internal logic fine tuned by learned from real-world experiences. While both strategies are essential, the successful interplay of their strengths leads to the dominance of one of them: co-creation.

We define adequacy in terms of improving or protecting viability, and we show that the four combinations of a coping and cocreation adequacy or inadequacy underlie the structure of identity in humans. The combinations also dictate how individuals attempt to protect and create the conditions for well-being, and their likelihood of success.

The notion of ontological security, as it is known in literature, is an accurate description of the coping mode's restricted capacity for the creation and protection of well-being. Ontological security leads to a self-limiting form of well-being that has been described as "abnormal normality".

Psychological safety provides the preconditions for high well-being and a safe environment promoting the healthy development of coping and co-creation adequacy.

\section{Key Words:}

Well-being, Ontological Security, Psychological Safety, Coping, Co-Creating, Core Cognition, Identity. 
In this theory paper we rigorously formulate the evolutionary roots of well-being from first principles, namely the basic demands of being and remaining alive. We identify two strategies and associated behavioral ontologies to create and protect the conditions for human well-being. Given space limitations and the breadth of the topic we limit ourselves to five sections. In section 1 we derive core cognition from first principles as the necessary foundational cognition shared by all of life in the service of being (well). This section ends in a summary table of core cognition defining terms. Section 2 describes the opposing and complementary properties of cognition for survival (coping) and cognition for flourishing (co-creation). This section is summarized in Table 2 in which we oppose and contrast the key terms of both modes of cognition as separate ontologies. Section 3 uses the developed core cognition framework to shed an explanatory light on the structure of identity by connecting it to coping and co-creation (in)adequacy. In section 4 we apply core cognition insights on a metatheoretical level. We contrast the theory of ontological security, as a near perfect example of the coping mode's (only) route to well-being, to the "theory" of psychological safety. This is as a typical example of the cocreation mode's route to flourishing. In section 5 we summarize and offer some pointers for future applications.

We define a large number of concepts in bold. If these concepts pertain generally to core cognition their definition is included in Table 1. If the concept, or a specific variant of it, pertains to either coping or co-creation it is listed in Table 2. Together the concepts of either list form behavioral ontologies for coping and cocreation. Table 2 is organized such that concepts with matching roles in coping and co-creation are grouped. The tables and figures form a summary of this paper.

\section{Section 1 - Core Cognition}

Is well-being unique for humans, or animals, or does it pertain to life in general? We argue that well-being is a foundational concept that can best be understood as pertaining to all living entities through a shared motivation for survival and thriving. In this section we define a set of key terms defining this core cognition (Andringa, van den Bosch, \& Wijermans, 2015): the foundational cognition shared by all of life to secure its continued existence and flourishing. We show that core cognition allows us to unify a number of well-known - but still unconnected - phenomena in psychology such as the structure of identity, and the two concepts of safety/security. Our starting point is that all living agents (all life) have the ability to extend their behavioral repertoire and make individual behaviors more effective for surviving and thriving.

\section{Being by doing}

A living entity is different from a dead entity because it selfmaintains this difference. To live entails a perpetuating process of self-maintaining and self-construction a 'far-from equilibrium state'. The work of Prigogine (1973) showed that, for thermodynamic reasons, such an inherently unstable system can only be maintained through a continual throughput of matter and energy (e.g., food and oxygen). Death coincides with the moment self-maintenance is no longer continued. From this moment on, the formerly living entity moves towards equilibrium and becomes an integral and eventually indistinguishable part of the environment.

A living entity 'is' - exists - because it 'does': it satisfies its needs by maintaining the throughput of matter and energy. It does this by "adaptively regulating its coupling with its environment so that it sustains itself" (Barandiaran, Di Paolo, \& Rohde, 2009 pp. 8; Andringa, van den Bosch, \& Wijermans, 2015). An autonomous organization that does this is called a living agent or an 'agent' in short (Barandiaran, Di Paolo, \& Rohde, 2009). Note that we refer to an agent when it pertains to life in general and is part of core cognition. Where we specifically refer to humans we use the term 'person'. The term 'individual' can refer to both, depending on context.
Living is precarious (Di Paolo, 2009) in the sense that it must be maintained actively in a world that is often not conducive to it and where both action and inaction can have high viability consequences (including death). We refer to 'behavior' as agentinitiated context-appropriate activities with expected future utility that counteract this precariousness and minimize the probability of death. Behavior is always aimed at remaining as viable as possible since harm - as viability reduction - can easily end a low viability existence.

A pattern of behaviors that effectively optimizes viability leads to flourishing, while a pattern of ineffective behaviors leads first to languishing and eventually to death. Life is "being by doing" (Froese \& Ziemke 2009, pp. 473) the right things. Viability is a holistic measure of the success or failure of "doing the right things" since it is defined as the probabilistic distance from death: the higher the viability, the lower the probability of the discontinuation of life. A walrus falling off a cliff can be perfectly healthy, but it has zero viability since it will die the moment it hits the ground. While healthy, it is in mortal and inescapable danger and hence unviable. In general, danger signifies a reduction of context appropriate behavioral options to include only those that allow the agent to survive. Maximizing viability (flourishing) and minimizing danger (survival) constitute basic motivations of life. In fact, we call any system cognitive when its behavior is governed by the norms of the system's own continued existence and flourishing (Di Paolo \& Thompson, 2014). This is also a reformulation of "being by doing."

\section{Cognition for survival and thriving}

Cognition entails behavior selection for survival - avoiding death - and thriving - (Barandiaran, Di Paolo, \& Rohde, 2009) optimizing viability of self and habitat. We have argued that cognition for survival is quite different from cognition for thriving (Andringa, van den Bosch, \& Wijermans, 2015). Cognition for survival is aimed at solving problems, where a problem is any perceived threat to agent viability interpreted as a pressing need motivating reactive behavior. We called this form of cognition coping. In humans, (fluid) intelligence is a measure of problem-solving capacity and manifests coping. The objective of coping is ending/solving the problems that activated the coping mode, so ideally coping is a temporary state. We refer to the problem-solving ability as intelligence.

However, when the agent's problem solving is inadequate and problems are not solved and potentially worsened or increased, the perceived viability threat remains activated and the agent is trapped in the coping mode of behavior. A coping trap keeps the agent in continued threatened viability and, hence, in behaviors aimed at short-term self-protection in suboptimal states that are far from flourishing. Maslov calls this deficiency (D) cognition (1968) since it is ultimately activated by unfulfilled needs. It is a sign that the intelligence of the agent's failed to end (solve) problem states.

While the coping mode of behavior is for survival, the co-creation mode is for flourishing. Successful coping leads to solved problems and satisfied needs and, hence, to its deactivation. Therefore, co-creation is the default mode of cognition and coping is - ideally - only a temporary fallback to deal with a problematic situation. Continued activation is the success measure of the cocreation mode and avoiding problems (or dealing with them before they become pressing) is the main objective of co-creation and it is proactive behavior. Maslow (1968) refers to this as being (B) cognition and we call it generalized wisdom here for reasons that will become apparent. The objective of co-creation is proactively producing indirect viability benefits through self-guided habitat contributions that improve the conditions for future agentic existence.

This is known as stigmergy: building on the constructive traces past behaviors left in the environment (Doyle \& Marsh, 2013; Gloag et al., 2013; Heylighen, 2016b; 2016a) and that - in the aggregate - gradually increase habitat viability. This expresses authority as a shaping force in the habitat (Marsh \& Onof, 2008) through influencing others, via habitat influencing. Habitat is 
defined as the environment from which agents can derive all they need to survive (and thrive) and to which they contribute to ensure long-term viability of self and others. Habitat viability is a measure of the potential of the habitat to satisfy the conditions for agentic existence (i.e., satisfies agentic needs). For example, a habitat can be deficient in the sense that its inhabitants are continually need deficient (and hence in the coping mode) or rich so that pressing needs can easily be satisfied and co-creative contributions help to perpetuate or enhance habitat viability further.

The biosphere grew from fragile and small to robust and extensive, so we know beyond doubt that life on Earth is, in the aggregate, a constructive force. It is the co-creation's contributions to habitat viability that explain this. In fact, the biosphere can be seen as the outcome of stigmergy: the sum total of all agentic traces left in the environment since the beginning of life (Andringa, van den Bosch, \& Weijermans, 2015). Co-creation and generalized wisdom as main cognitive ability drives the biosphere's growth and gradually increases the carrying capacity of the biosphere, which makes co-creation the most authoritative influence on Earth. Coping, to a lesser degree, is also an important authoritative influence.

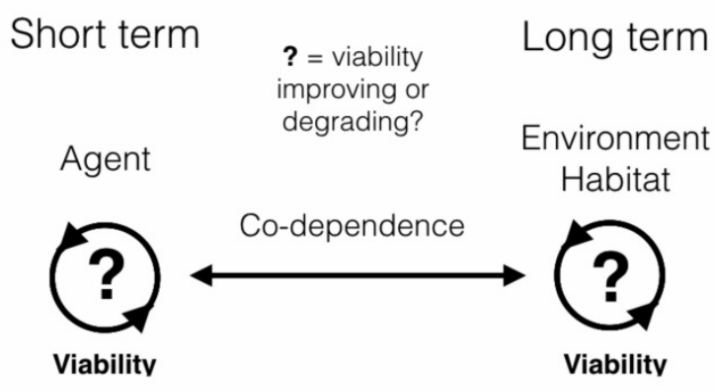

Figure 1 Life's demand: maintaining viability of self and habitat (based on Andringa \& Angyal, 2019).

Figure 1 presents the co-dependence of acting agents on their habitat. The habitat comprises the aggregate of agentic activities, but is not an actor itself. Hence, a viable habitat is composed of the sumtotal of previous co-creative agentic traces that form a resource to satisfy the conditions on which current agentic existence depends. This entails that, signified by the question marks, agents should be aware not only of their own viability, but also of habitat viability. In fact, we have argued that early, primitive life forms were yet unable to separate self from the combination of self and habitat. This leads to an "original perspective" on the combined viability of agent and habitat, which allowed their primitive cognition to optimize the whole, while addressing selfish needs and creating ever better conditions for agentic life (Andringa, van den Bosch, \& Weijermans, 2015).

\section{Well-being and adequacy}

We argue that this is the natural root of the concept of well-being. We propose that successful well-being, with a focus on 'being' and hence interpreted as a verb, can best be understood as a cocreation process leading to high viability agents, increased habitat viability, and long-term protection of the conditions on which existence depends.

The two modes of behavior have quite different impacts on the habitat and, by extension, the biosphere. The coping mode is aimed at protecting and improving agent viability with whatever means the agent has access to. Since the objective is avoiding death, the motivation is high, which entails that habitat resources can be sacrificed for self-preservation purposes. Inadequacy can be defined as the tendency to self-create, prolong, or worsen problems that keep an agent in the coping mode. And when a habitat is dominated by inadequate agents, habitat viability cannot be maintained, let alone increased. From the perspective of coping, the world is at best a zero-sum game.
Alternatively, adequacy can be defined as the ability to avoid problems or end them quickly so that coping is rare and effective and co-creation prevalent so that habitat viability is protected, its carrying capacity increases, and long-term need satisfaction is secured. Co-creation is, like the term suggests, a more than zero sum game. This is, as argued above, the true basis of well-being. Due to its lack of "co-creation", coping can only protect lower levels of well-being and, at best, resolve (or otherwise take care of) viability threats (in the sense of removing symptoms of low well-being), while co-creation allows both agent and habitat flourishing.

\section{Behavioral repertoire and worldview}

Living agents, per definition, need to express behavior to perpetuate their existence. And with every intentional action, it implicitly relies on the set of all that the agent takes as reliable (i.e., true in the sense of reflecting reality as it is) enough to base behavior on. We refer to this set as the agent's worldview. A worldview should be a stable basis, as well as developing over time because it is informed by the individuals's learning history. An agent's worldview informs its appraisal of the immediate environment. This may be an appraisal of its viability state: whether the habitat is safe or not, or whether it judges the current situation manageable, too complex, or opportunity filled.

These are basic appraisals shared by all of life that seem to be reflected in the psychological concept of core affect (Russell, 2003). Core affect is a mood-level construct that combines the axis unpleasureable-pleasurable with an arousal axis spanning deactivated to maximally activated. Core affect is intimately and bidirectionally linked to appraisal (Kuppens, Champagne, \& Tuerlinckx, 2012) and directly refers to whether one is free to act or forced to respond: whether one can co-create proactively or has to cope reactively. Hence appraisal is a worldview-based motivational response to the perceived viability consequences of the present state of the world. It is motivational, but not yet action. As such appraisal resembles Frijda's (1986) emotion definition as 'action readiness'. Which fits with the notion that all cognition is essentially anticipatory.

\section{"Cognitive systems anticipate future events when selecting actions, they subsequently learn from what actually happens when they do act, and thereby they modify subsequent expectations and, in the process, they change how the world is perceived and what actions are possible. Cognitive systems do all of this autonomously." (Vernon 2010, pp. 89).}

Core affect is a psychology term (Russell, 2003) that we here generalize to all of life. The human worldview is, of course, filled with explicit and shared beliefs, opinions, facts, or ideas interpreted with and filtered by experiential knowledge. But the basis is the same for a general agent: if the agent judges the situation safe it can relax since it has to satisfy few constraints If the situation is safe and opportunity-filled it can be interested and learn. But if the situation imposes many constraints, it tries to end these by establishing control. And in a deficient environment it is devoid of opportunities (which in humans may correspond to boredom or sadness in case of lost opportunities). Core affect then corresponds to basic motivations: to perpetuate, to aim for, to end, and to avoid. We have depicted this in Figure 2.

Appraisal of reality refers to the behavioral consequences of the current state of the world and it is a form of basic meaning-giving that activates a subset of context appropriate behavioral options. This leads to motivation as being ready to respond in a certain way. We define the set of all possible - appraisal and worldview dependent - behaviors as the behavioral repertoire. The richer the behavioral repertoire, the more diverse context appropriate behaviors the agent can exhibit. The more effective its behavioral repertoire, the more effective it becomes in realizing intended outcomes. 


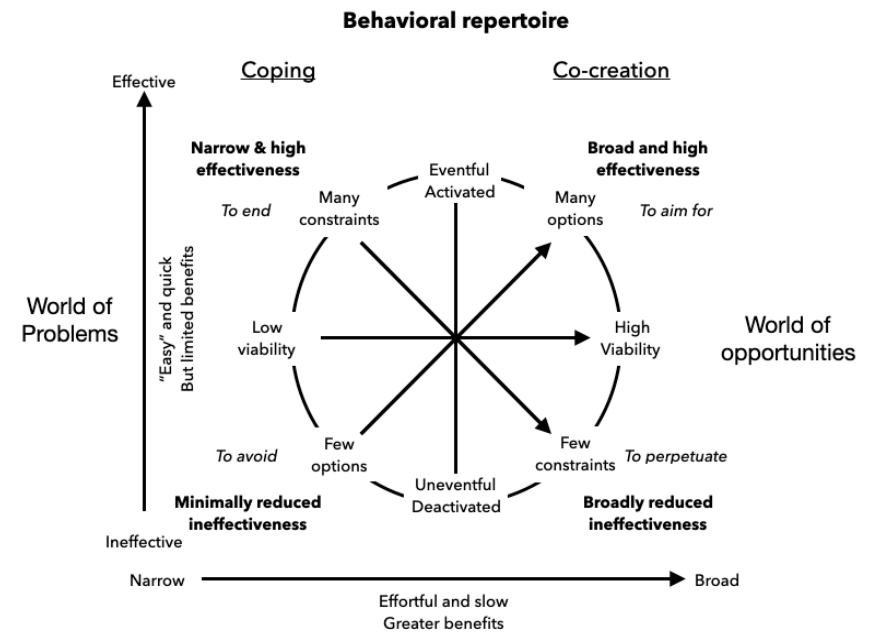

Figure 2 Behavioral repertoire. The concepts in the circle refer to appraisal and the verbs in italic to basic motivations. The descriptions in bold and the outer axes refer to the structure of behavioral (in)effectiveness.

Learning reduces the scope of the ineffectiveness and/or increases effectiveness. Reducing the scope of ineffectiveness is an individual discovery path through a representative sample of different environments. Broadening is effortful and potentially risky but ultimately rewarding. The broaden and build theory (Fredrickson \& Branigan, 2005) fits with this frame by connecting positive emotions to extending the scope of behavior. Increasing effectiveness may entail adopting the behaviors of (seemingly) more effective agents. This is a quick fix and works wherever the adopted behaviors remain effective. Used predominantly, this leads to agents whose adequacy is conditional to a narrow set of situations in which they feel adequate. These agents may be highly protective of their "islands of adequacy".

\section{Core cognition core terms}

This discourse leads to a summary of core cognition key concepts and their definition that is presented in Table 1

\section{Section 2 - Coping and co- creation}

This section addresses the quite different and complementary features of coping and co-creation. We need both, because successful coping ensures ample time for co-creation. This complementarity of the two modes, as two separate ontologies that disagree on many aspects, might be the root of life's resilience.

Coping and co-creation are abilities (in psychology, skills and tacit knowledge expressed as behavior in response and appropriate to how the agent appraises its habitat context. Of course, agent-initiated actions change the habitat state to which other agents may respond, which, in turn, changes the habitat state. Since the habitat may change even without direct agentic influences, agents exist in an evolving world in which they must position themselves to protect and enhance self and habitat viability. To exist in such an environment, the agent needs anticipatory models (Vernon, 2010) of the state of self and the habitat. It must update these actively, and choose its behavior to realize benefits to self and the habitat. In this open environment, even the best agent generated model leads only to partial predictability. Coping and co-creation strategies rely on partial predictability to improve predictability but via different and complementary logics.

\section{Coping}

Coping makes the world more predictable by reducing its complexity and creating systems (of agents or objects) with more predictable behavior that bring threats-to-self under control which requires energy, resources, and continual maintenance and promote security. The coping mode's goal is to end perceived viability threats, and coping success entails the discontinued need for its activation. Hence, it is goal-oriented (like problem-solving) and endowed with a sense of urgency to avoid (further) viability deterioration that justifies the exploitation of previously created viability. Any deviation from manageable order - unfamiliar events or deviant agent behavior - is seen as an unwanted intrusion to be counteracted. Hence, coping leads to an effortfully controlled environment that minimizes unpredictability and diversity. If the threat level - i.e., the expected negative viability impact - increases, so does the drive to suppress diversity.

Since coping is goal-oriented and aiming to reduce complexity, it favors shared rules (in general shared knowledge). The more agents follow the same rules with great precision, the more predictable agents and the habitat become. Coping promotes the spread and precise execution of a single set of behavioral rules as well is an urge to correct or suppress any unwanted diversity. This is a form of social mirroring that might not only lead to the spread of effective behavior, but also to lead to a "degree of entanglement" (Combs \& Kribner 2008, pp. 264), emergent collective behavior, and a group level perspective.

In human societies, bureaucracy, the military, large corporations, and strict manifestations of religions and ideologies are examples of the coping logic. Technology, from very primitive to complex like computers, shows the best of coping by producing precise outputs as long as the physical environment (the tool and its necessary resources) and the user operate within very tight constraints (which entails skilled behaviors).

Imposing limits on agentic behavior works best for agents who expect benefits from it. Agents with similar needs might share a similar sense of coordination benefit, but that is unlikely for agents with different needs or those with other (even potentially better) strategies. In fact, imposed external coordination might be detrimental to some. These differences in expected outcome lead to a separation in in-groups and out-groups. An in-group is a group of agents who share adequacy limits and, hence, share perceptions of what is beneficial, and how to realize these benefits. Out-groups do not share these limits, either because they have other limits or because they are less limited. Irrespective of their limits, out-groups frustrate coordinated coping in the eyes of in-groups. Note that out-groups might not even know they are assigned to the out-group and might not raise their defenses.

In-groups see the risk of frustrated coordinated behavior as an existential threat which justifies exploiting or suppressing outgroups and the habitat alike. Habitat and out-group exploitation may activate resistance that makes goal achievement more difficult. So, the better the in-group is able to control out-groups and habitat, the more likely they are to realize intended results. Due to its problem-solving nature, coping manifests "the ability to realize intended outcomes". Which is Bertrand Russell's (1938) definition of power. Hence coping behaviors are a manifestation of power generalized to generic agents.

The coping mode's manifestation of authority are typically power based in the sense that it sets-up habitat conditions for reduced diversity and increased predictability of agent behavior. This is known as coercive authority as opposed to legitimate power (hofman et al, 2017). Coercive power, generally (but not necessarily) lead to benefits for the in-group at the detriment to out-groups and the wider habitat: the zero-sum game that in humanity is associated with manifestations of authoritarianism. 
Core cognition key concepts with definition

\begin{tabular}{|c|c|}
\hline Core Cognition & The cognition shared by all of life \\
\hline To live & Self-maintaining being different from the environment \\
\hline Death & End of self-maintained difference from the environment \\
\hline Need satisfaction & Acquiring and executing the necessities (food and energy) for life (self-maintaining being different from the environment) \\
\hline Agent & $\begin{array}{l}\text { "An autonomous organization that adaptively regulates its coupling with its environment and contributes to sustaining itself as a } \\
\text { consequence." (Barandiaran, Di Paolo, and Rohde 2009, pp. 1) }\end{array}$ \\
\hline Behavior & $\begin{array}{l}\text { Agent-initiated and context-appropriate activities with expected future utility that counteract life's precariousness and maximizes } \\
\text { agent and habitat viability. }\end{array}$ \\
\hline A need & Something that, when satisfied, protects or increases viability \\
\hline Viability & Probabilistic distance from death (i.e., discontinued agency) \\
\hline Agency & The ability to self-maintain viability (through need satisfaction) for survival and thriving \\
\hline Agent viability & Agent probabilistic distance to death. To persist all life needs to optimize viability \\
\hline Cognition & The ability to select behavior in the service of the agent's continued existence and flourishing. \\
\hline $\begin{array}{l}\text { Coping and } \\
\text { co-creation }\end{array}$ & $\begin{array}{l}\text { Two complementary forms of cognition. Coping is in the service of continued existence and flourishing in the service of } \\
\text { flourishing. (These two forms of cognition are opposed in table 2) }\end{array}$ \\
\hline Stigmergy & Building on the constructive traces that past behaviors left in the environment (increasing habitat viability) \\
\hline Authority & Expressing stigmergy" \\
\hline Habitat & $\begin{array}{l}\text { The environment from which agents can derive all they need to survive (and thrive) and to which they contribute to ensure long- } \\
\text { term viability (of self and others), Note that we use the term habitat to include other agents, but to exclude the agent. Hence, we } \\
\text { can speak of agent + habitat to refer to the whole of existence relevant to the agent }\end{array}$ \\
\hline Habitat viability & A measure of the degree to which the habitat can satisfy the conditions for agentic existence (i.e., satisfies its needs) \\
\hline Biosphere & $\begin{array}{l}\text { The sumtotal of all agentic traces left in the environment. Since the biosphere grew from fragile and small, to robust and } \\
\text { extensive we can conclude that life is a net constructive force and co-creation has been dominant }\end{array}$ \\
\hline Carrying capacity & A measure of the sumtotal of the life activities that a habitat can sustain \\
\hline Well-being & $\begin{array}{l}\text { Process of co-creation leading to high viability agents, increased habitat viability and long term protecting of the conditions on } \\
\text { which existence depends. Note this is a process, not a state or the evaluation of a state. }\end{array}$ \\
\hline Affordances & $\begin{array}{l}\text { "The affordances of the environment are what it offers the animal, what it provides or furnishes, either for good or ill. ... It implies } \\
\text { the complementarity of the [agent] and the environment." (Gibson, 1979, p. 127) }\end{array}$ \\
\hline Context & Agent's assessment of the (current) state of the habitat \\
\hline $\begin{array}{l}\text { Behavioral } \\
\text { repertoire }\end{array}$ & The set of context appropriate behaviors the agent has access to \\
\hline Learning & The process to extend the behavioral repertoire and tune its effectivity to the context \\
\hline World-view & The set of all that an agent takes as reliable (true) enough to base behavior on. \\
\hline Appraisal & A worldview-based motivational response to the perceived viability consequences of the present. \\
\hline Core affect & Mood level action readiness based on the appraisal of indicator of (un)safety and situationally appropriate activation. \\
\hline Realism & A measure of whether individual behavior leads to intended and/or viability enhancing outcomes \\
\hline Identity & A theory-of-me-as-actor-in -the-world \\
\hline Resilience & $\begin{array}{l}\text { "the capacity of a system to absorb disturbance and reorganize while undergoing change so as to still retain essentially the same } \\
\text { function, structure, identity, and feedbacks" (Walker et al., 2004) }\end{array}$ \\
\hline
\end{tabular}




\section{Co-creation}

Co-creation does not reduce complexity, instead it makes the world more predictable by promoting unconstrained natural behavior and easy need satisfaction through promoting and communicating efforts that facilitate and maintain habitat viability. This creates a safe environment where safety is defined as "a situation or state with positive indicators of the absence of viability threats." This communicated absence of threats is a logical necessity since an absence can otherwise not be established. The positive indicators of safety - signs of unforced agentic behavior - allow agents in the habitat to co-create without having to be alert for (unexpected) danger. This allows the uninterrupted functioning of a self-organizing network of interacting agents that satisfy needs most naturally, while minimizing negative impacts and promoting coexistence and even collaboration. Human friendships depend on this logic and they have, like all co-creation processes, no stable outcome or goal other than providing a safe context for growth and flourishing.

This is the complement of imposing limits on other agent's behavior (which characterizes coping). Unconstrained natural behavior does not need guidance, since the agents do whatever comes naturally and return to this when constraints are lifted. This harmony between what is allowed and what comes naturally, stabilizes the habitat, leads to more communicated safety, and increases predictability through the reduction of interagent tension that otherwise might activate coping as fallback. Co-creating agents should become aware of the needs of others and what comes naturally to themselves, others with similar needs, others with different needs, and the wider habitat's dynamics. They have to optimize all in the context of everything else and over all timescales (we referred to this as 'pervasive optimization', Andringa et al. 2015), which is a direct reference to Sternberg's definition of wisdom:

"The application of tacit knowledge towards the application of a common good through a balance among intra-, inter-, and extrapersonal interests to achieve a balance among adaptation to existing environments, shaping of existing environments, and a selection of new environments, over the long term as well as the short term." Sternberg (1998)

This definition is somewhat human-centered and can easily be generalized to all life, all agentic interests, all habitats, and all time-scales. And since tacit knowledge refers to skills, Sternberg's definition can be generalized to "the balancing skills to contribute to the biosphere." This is what we refer to as generalized wisdom. The addition of 'generalized' signifies the importance of constructive skills and the real-world impacts whilst deemphasizing the explicit knowledge component.

Where the application of power generally (but not necessarily) produces benefits to an in-group at the detriment of out-groups, proper co-creation leads to broadly constructive benefits and is a more than zero-sum game. As we argued, this drove and arguably still drives biospheric growth. Note that many agents might still suffer; the argument is broad net benefits, not the absence of harm or suffering.

Co-creating agents need to act on what comes naturally to agents and habitats. They must learn how to promote more natural behavior and prevent behavior leading to broadly detrimental consequences. The Daoist key term 'Wu Wei,' reflects this since it "means something like 'act naturally, ' effortless action,' or 'nonwillful action'" (Littlejohn, 2003). Characteristically, it completely misses the urgency of coping strategies and the effort associated with exercising power. Wu Wei is also a way to be authoritative:

individuals emerge authoritative and powerful as part and parcel of an interconnected web of forces. Therefore, a crucial back-andforth tug between the self and the various influences and authorities surrounding it is woven in the very fabric of what it means to be a fully attained and empowered individual." (Brindley, 2010, pp. xxvii-xxviii).

Wu Wei is a quite different conception of authority since it does not pertain to realizing specific intended results, but instead is aimed at pervasive optimization (Andringa et al., 2015) and becoming "a fully attained and empowered individual" as "part and parcel of an interconnected web of forces"; what Maslow refers to as self-actualization. It is this growth process that drives, identity development, as much as it promotes general well-being.

\section{Two ontologies}

The complementary properties and behavioral logic of coping and co-creation lead often to opposing strategies. Both aim to increase habitat predictability. Coping does that via imposing behavioral constraints and habitat control to counteract adequacy limits. Co-creation instead promotes the creation of a never stable network of behaviors that come naturally and unconstrained and that distribute the responsibility for habitat viability over all contributing agents. Implicitly this assumes that participants are willing and able to alleviate their adequacy limits and grow in their ability to co-create.

Coping and co-creation are both essential. But successful coping is short and effective, it ends the cause for its activation and restores co-creation as behavioral default. Unsuccessful coping is ineffective, and hence prolonged. And since the causes for its activation remain valid, it precludes co-creation. This entails that individuals who predominantly cope or co-create develop quite different worldviews, strategies, values, and identities. Hence they might not be able to understand one another.

Table 2 shows the two separate ontologies of coping and cocreation. It organizes and relates the concepts within each ontology through matching them to complimentary concepts and/or roles in the other ontology. That we are able to do that on a consistent basis, suggests not only the structural differences between coping and co-creation, but also that we are uncovering some basic of tenets of life and cognition.

We consider the selection, matching, and precise formulation of these concepts an ongoing process. Hence, its formulations will develop over time; the formulation in the table is our current best.

\section{Section 3 - Identity: learning co-creation and coping}

Sections 1 and 2 focused on a derivation, mainly from first principles, of core cognition and its two complementary behavioral modes - coping and co-creation - as it pertains to a generic living agent. The current section makes the transition to human cognition by applying the current formulation of core cognition to human identity development. Identity development can be interpreted as the development of agency (here in humans), which explains why we choose this topic. This section leads both to an enriched understanding of the interplay between coping and co-creation, as well as a demonstration that the conceptual language of core cognition is a productive tool to approach psychological phenomena.

\section{Identity development}

Berzonsky describes identity as a self-generated theory of me as an actor in the world, or self-theory: an explanatory structure constructed to explain and plan one's interactions with the world. It is the basis of understanding one's position and role in the world and, hence, an expression of one's worldview. The selftheory allows one to cope with challenges and respond to opportunities and in return these enrich the self-theory and one's 


\begin{tabular}{|c|c|c|c|}
\hline \multicolumn{2}{|r|}{ Ontology of survival (coping) } & \multicolumn{2}{|l|}{ Ontology of thriving (co-creation) } \\
\hline Languishing & $\begin{array}{l}\text { Low viability state as the outcome of a pattern of ineffective } \\
\text { or limited behaviors }\end{array}$ & $\begin{array}{l}\text { High viability state as the outcome of a pattern of broadly } \\
\text { effective behaviors }\end{array}$ & Flourishing \\
\hline Danger & $\begin{array}{l}\text { Agent appraisal of viability threats, entailing a reduction of } \\
\text { the set of context appropriate behavioral options to include } \\
\text { only those that allow the agent to survive. }\end{array}$ & $\begin{array}{l}\text { Agent appraisal of the absence of viability threats, } \\
\text { entailing an enlarging of the set of context appropriate } \\
\text { behavioral options to include only those that allow the } \\
\text { agent to survive. }\end{array}$ & Safety [freedom] \\
\hline Problem & $\begin{array}{l}\text { A perceived threat to agent viability that activates a pressing } \\
\text { need and hence motivates reactive behavior }\end{array}$ & $\begin{array}{l}\text { A perceived possibility to improve (agent or habitat) } \\
\text { viability and hence motivates proactive behavior }\end{array}$ & Opportunity \\
\hline Coping & $\begin{array}{l}\text { The reactive fallback mode of behavior aimed at protecting } \\
\text { agent viability by ending problem states. Quick and effective } \\
\text { deactivation of coping is the measure of success of the } \\
\text { coping mode }\end{array}$ & $\begin{array}{l}\text { The pro-active default mode of behavior aimed at } \\
\text { producing indirect viability benefits through habitat } \\
\text { contributions that improve the conditions for future } \\
\text { agentic existence }\end{array}$ & Co-creation \\
\hline Reactive behavior & Behavior in response to perceived threats to viability & $\begin{array}{l}\text { Behavior aimed at setting up or protecting the conditions } \\
\text { for co-creation }\end{array}$ & Proactive behavior \\
\hline $\begin{array}{l}\text { Main mode of } \\
\text { cognition: } \\
\text { Intelligence }\end{array}$ & $\begin{array}{l}\text { The ability to solve problems (or end states of pressing } \\
\text { needs) }\end{array}$ & $\begin{array}{l}\text { The ability to avoid problems and co-create: (Also: The } \\
\text { balancing skills to contribute to the biosphere) }\end{array}$ & $\begin{array}{l}\text { Main mode of } \\
\text { cognition: Practical } \\
\text { wisdom }\end{array}$ \\
\hline $\begin{array}{l}\text { Coping trap } \\
\text { (Coping failure) }\end{array}$ & $\begin{array}{l}\text { The continual or predominant activation of the coping mode } \\
\text { of behavior through ineffective or counterproductive } \\
\text { problem-solving strategies. }\end{array}$ & Prolonged or near continual activation of co-creation. & $\begin{array}{l}\text { Successful co- } \\
\text { creation }\end{array}$ \\
\hline Inadequacy & $\begin{array}{l}\text { The tendency to self-create, prolong, or worsen problems } \\
\text { that keep on activating the coping mode. An inadequate } \\
\text { agent is predominantly coping, but unsuccessful in ending } \\
\text { the activators of coping. }\end{array}$ & $\begin{array}{l}\text { The skill to avoid problems or end them quickly so that } \\
\text { coping is rare and co-creation prevalent. An adequate } \\
\text { agent is a predominant co-creator }\end{array}$ & Adequacy \\
\hline Coping adequacy & $\begin{array}{l}\text { The skill to solve pressing problems (ending the need to } \\
\text { cope) or mitigate their impact through control of the } \\
\text { environment and constraining agency (continuing coping) }\end{array}$ & $\begin{array}{l}\text { The skill to avoid and end problems through harmonizing } \\
\text { relations and (inter-agent) conflict mitigation. }\end{array}$ & $\begin{array}{l}\text { Co-creation } \\
\text { adequacy }\end{array}$ \\
\hline Power & $\begin{array}{l}\text { The ability to realize intended outcomes by effortfully } \\
\text { shaping and controlling the habitat and the activities of the } \\
\text { agents that comprise it. Exercising power is a way to be } \\
\text { authoritative. }\end{array}$ & $\begin{array}{l}\text { Effortless action aimed at being authoritative through } \\
\text { harmonizing a diversity of agentic interests by promoting } \\
\text { natural agentic dynamics and development. }\end{array}$ & Wu wei \\
\hline Security & $\begin{array}{l}\text { A situation or state where viability threats-to-self are brought } \\
\text { under control }\end{array}$ & $\begin{array}{l}\text { A situation or state with positive indicators of the absence } \\
\text { of viability threats }\end{array}$ & Safety \\
\hline $\begin{array}{l}\text { Well-being - short } \\
\text { term }\end{array}$ & Self-evaluation of own agentic viability & Holistic self-valuation of own and habitat viability & $\begin{array}{l}\text { Well-being - long } \\
\text { term }\end{array}$ \\
\hline $\begin{array}{l}\text { Ontological } \\
\text { security }\end{array}$ & $\begin{array}{l}\text { the secure feeling an individual derives from attaining "on } \\
\text { the level of the unconscious and practical consciousness, } \\
\text { 'answers' to fundamental existential [problems] which all } \\
\text { human life in some way addresses" (Giddens, 1991) }\end{array}$ & Realizing full individual potential & Self-actualization \\
\hline $\begin{array}{l}\text { Ontological } \\
\text { security }\end{array}$ & $\begin{array}{l}\text { I need others to limit my inadequacy } \\
\text { I rely on rules and routines } \\
\text { I adhere to roles } \\
\text { I protect the system }\end{array}$ & $\begin{array}{l}\text { I can join freely } \\
\text { I can learn freely } \\
\text { I can contribute freely } \\
\text { I can criticize freely }\end{array}$ & $\begin{array}{l}\text { Psychological } \\
\text { safety }\end{array}$ \\
\hline "Habitualization" & $\begin{array}{l}\text { The consolidation of routines via reference to socially } \\
\text { constructed rules and routines, sustaining a group identity } \\
\text { and the security on derives from in-group membership. }\end{array}$ & $\begin{array}{l}\text { An attempt to liberate oneself from imposed limits on self- } \\
\text { guided behavior and the restoration of the safety } \\
\text { associated with co-creative processes. }\end{array}$ & Reactance \\
\hline in-group & $\begin{array}{l}\text { A group of individuals sharing similar limits on adequacy } \\
\text { (and worldview) }\end{array}$ & \multirow{2}{*}{$\begin{array}{l}\text { A group of individuals that each freely and self-guided } \\
\text { contribute whatever benefit their adequacy can bring. }\end{array}$} & \multirow{2}{*}{ Community } \\
\hline Out-group & $\begin{array}{l}\text { Individuals who are not in-group and hence frustrate } \\
\text { coordinated coping }\end{array}$ & & \\
\hline Othering & $\begin{array}{l}\text { The process of assigning individuals with other or less limits } \\
\text { to adequacy to out-groups (possibly disgust driven) }\end{array}$ & Unconditional acceptance & Acceptance \\
\hline $\begin{array}{l}\text { Abnormal } \\
\text { normality }\end{array}$ & $\begin{array}{l}\text { Complete and symptomless adaptation to a world shaped } \\
\text { through coping that imposes limits on individual agency and } \\
\text { self-development }\end{array}$ & $\begin{array}{l}\text { The ability to co-create in a world dominated by co- } \\
\text { creation allowing unlimited development and expression } \\
\text { of agency and self-development. }\end{array}$ & Healthy normality \\
\hline Normative threat & $\begin{array}{l}\text { Threats to oneness (shared authority) and sameness } \\
\text { (shared values and rules) }\end{array}$ & $\begin{array}{l}\text { Perceivable indications of agents being engaged in } \\
\text { unforced activities. }\end{array}$ & Indicators of safety \\
\hline
\end{tabular}

Table 2: Core cognition terms as pertaining to either coping or co-creation. Together these form an ontology for survival (coping) and an ontology for flourishing (co-creation). Pairs with matching roles across the coping--co-creation boundary are listed in the same row 
worldview. Berzonsky (1989), quoting Epstein, describes this selftheory as

\begin{abstract}
"a theory that the individual has unwittingly constructed about him- or herself as an experiencing, functional individual ... it contains major postulate systems for the nature of the world, for the nature of the self, and their interaction. Like most theories, that selftheory is a conceptual tool for accomplishing a purpose. Major purposes are to optimize the pleasure/pain balance of the individual over the course of a lifetime ... and to organize the data of experience in a manner that can be coped with effectively."
\end{abstract}

Learning to optimize the pain/pleasure balance fits very well with optimizing well-being of self through self-development of a worldview and adequate behavioral repertoire for coping and cocreation. According to Berzonsky, the effectiveness of a selftheory can be measured in terms of whether it helps "to solve the personal problems it was constructed to handle [and] does it serve as a framework within which experience and [...] relevant information can be meaningfully organized and understood" (1989). We refer to this (partial) effectiveness as (partial) adequacy.

James Marcia (1967) described late-adolescent development in terms of a transition from the "the given" (the dependent) to the (independent) "givers" and an identity (development) crisis. He described (1966) four identity statuses as combination of high and low scores on two dimensions: stable commitments and (in a modern formulation) deliberate self-exploration.

1. Stable commitments indicate that personal strategies are effective and, hence, that one can build - with coping or co-creation strategies - on traces left in the habitat (stigmergy, authority). Since effective strategies further improve through experience, they do not have to be replaced, which leads to stable, albeit developing, lifestrategies. And therefore, a stable and effective personality. In Figure 2, this corresponds to an "upward" move towards a more effective behavioral repertoire.

2. Deliberate self-exploration and the development of a theory of me as actor in the world is a requirement for the development of a unique self, rather than a self constructed on values and beliefs uncritically and unchanged adopted from others. The process of deliberate exploration of me as an actor in the world is a manifestation of the broadening of the behavioral repertoire. In Figure 2 we noted that broadening the behavioral repertoire is more effortful and slower than making it narrowly more effective. But since it contributes to co-creation capacity it offers higher longterm benefits and can be a preferred choice for individuals who have learned to value its benefits. This requires the development of co-creation's basic strategy of discovering and later using the unconstrained natural behavior of self, others, and wider habitat alike.

The shaping of a unique self occurs on the basis of shared or consensual adopted values, beliefs, and strategies to bootstrap self-development. Enacting a unique self requires a shift in perceived locus of causality (PLOC) from external to internal: "The more internalized a value or regulation, the more it is experienced as autonomous or as subjectively located closer to the self" (Ryan \& Connell 1989, pp. 750; Andringa et al., 2015).

PLOC internalization is not so much a rejection of previous values, beliefs, and strategies but a refinement of these by allowing individual experiences to enrich and generalize them so that they can be applied more flexibly (i.e., less rigid), more context appropriate (realistic), and more effectively in the long term: a change from explicit to tacit knowledge. PLOC internalization also corresponds to a move from group authority to individual authority and a greatly increased individual capacity for co-creation. The combined changes of PLOC, explicit to tacit, and from group to individual authority entail deep changes that warrant to be referred to as a crisis.

Identity research uses past or current self-exploration crises as a tell-tale indicator of identity development. We connect this crisis to the development of co-creation adequacy because the individual somehow understands its future benefits. Similarly, we couple a coping preference to a preference for complexity reduction and hence to the absence (or active avoidance) of a selfexploration. Table 3 shows this for the four established identity statuses (Berzonsky, 1989; 1966). We will discuss each in the next sections.

\section{Identity achieved}

An achieved identity develops from a negotiated self-exploration crisis that results in a well-explored stable identity. We couple this to adequate co-creation and coping skills that allow one to prevent most problems and quickly overcome problems when they occur. This entails that the individual can safely and effectively build on past efforts (stigmergy) and that produce few

\begin{tabular}{|c|c|c|}
\hline & $\begin{array}{l}\text { Coping preference } \\
\text { No deliberate self-exploration } \\
\text { PLOC external }\end{array}$ & $\begin{array}{l}\text { Co-creation preference } \\
\text { Deliberate self-exploration } \\
\text { PLOC internal }\end{array}$ \\
\hline $\begin{array}{l}\text { Adequate } \\
\text { coping } \\
\text { Stable } \\
\text { commitments }\end{array}$ & $\begin{array}{l}\text { Focused on dealing with viability threats to self } \\
\text { Focus on complexity reduction of habitat and agent behaviors. } \\
\text { Effective but targeted behavioral repertoire } \\
\text { Identity foreclosed } \\
\text { Self-exploration prevented through adoption of societal norms }\end{array}$ & $\begin{array}{c}\text { improving own and habitat viability } \\
\text { Focus on opportunities of self and habitat. Self-actualization due to } \\
\text { a broad and effective behavioral repertoire } \\
\text { Achieved identity } \\
\text { Self-exploration crisis negotiated resulting in well-explored stable } \\
\text { identity }\end{array}$ \\
\hline $\begin{array}{l}\text { Inadequate } \\
\text { coping } \\
\text { No stable } \\
\text { commitments }\end{array}$ & $\begin{array}{l}\text { Contributor to deficient viability of self and habitat } \\
\begin{array}{c}\text { Focus on strategies that mitigate (public exposure of) inadequacy. } \\
\text { Little self-development. Behavioral repertoire narrow and } \\
\text { minimally effective } \\
\text { Identity diffusion } \\
\text { Self-exploration avoided, in combination with a fluid or unstable } \\
\text { self-identity }\end{array}\end{array}$ & $\begin{array}{l}\text { Aimed at protecting the conditions for existence } \\
\text { Focus on broadening one's behavioral repertoire, mastering co- } \\
\text { creation strategies and developing a unique identity } \\
\text { Identity moratorium } \\
\text { Self-exploration crisis (still) in progress, not (yet) leading to } \\
\text { crystalized identity structure }\end{array}$ \\
\hline
\end{tabular}

Table 3. In normal font identity status related core cognition features. In italic, defining properties of four types of identity structures (based on Berzonsky, 1989) 
unintended and adverse side effects. With the achieved identity comes the informational identity style that Beaumont and Pratt (2011, pp 174) summarize as follows:

\begin{abstract}
... they address identity-relevant issues by being skeptical of their self-views, questioning their assumptions and beliefs, and exploring and evaluating information that is relevant to their selfconstructions [hence improving their worldview]. The use of an informational style is positively associated with strategic planning, vigilant decision making, and the use of proactive and problemfocused coping [indicating effective coping and co-creation]. The informational style is also associated with such personal and cognitive attributes as autonomy, openness to experience, introspectiveness, self-reflection, empathy, a high need for cognition, and a high level of cognitive complexity."[Text in block quotes added by the current authors].
\end{abstract}

These listed properties all facilitate high autonomy, selfdevelopment and effective real-world contributions characteristic of co-creation. And high well-being (Berzonsky \& Cieciuch, 2016) and wisdom as we have defined it.

\section{Identity moratorium}

Identity moratorium corresponds to an ongoing self-exploration crisis and self-development focus that, despite efforts to commit, did not yet lead to a stable identity structure. Although cocreation adequacy might not have been achieved, co-creation is still considered superior to coping and, hence, has become the dominant strategy. This entails that the moratorium expresses the strengths of co-creation through a focus on contributing to a highquality habitat, but that the strengths of coping: control of diversity and rapidly ending problems; is minimally expressed. This leads to less time co-creating than the achieved identity status. Moratoria express many of the features of the informational identity style, but to a lesser degree due to lower coping skills, which also leads to lower well-being than the achieved identity style (Berzonsky \& Cieciuch, 2016).

\section{Identity foreclosure}

Identity foreclosure corresponds to prevented self-exploration through the uncritical adoption of consensual norms. We argue that a foreclosed identity results from the - viability threat induced - dominance of the coping mode that favors group level rules and, in general, shared knowledge over individual knowledge. Foreclosed individuals aim to adopt and express shared rules with great diligence and they actively promote the adoption of a single shared worldview. This effectively curtails habitat diversity that is intended to end the threats that keeps the coping mode active.

If it does not, foreclosed individuals end up in a coping trap that, through their insistence on limiting the behaviors of others, might dominate the habitat. Foreclosed individuals are the only identity status who insist on others to change. Their (unspoken) motto is: "we are right and you have to adapt your behavior to match ours". They feel righteous because they have no access to perspectives and worldviews other than their own, and do not see benefits in other strategies than their own. The normative identity style of foreclosures can be summarized as follows:

"Normative individuals more automatically internalize and conform to the standards and expectations of significant others. Discrepancies between information about how they are and their normative standards evoke feelings of guilt and concern about avoiding failure [to be a good in-group member]. Their primary aim is to defend and maintain existing self-views [to protect a shared worldview]. (Berzonsky, 2008, pp 646)

Normative individuals report high levels of identity commitment as well as dispositional characteristics such as agreeableness, extraversion, and conscientiousness [facilitating rule following].
However, they also report low levels of openness and introspectiveness [foreclosing further identity development], Normative individuals have been found to employ avoidant coping strategies, to procrastinate in the face of [individual] decisions, to have a high need for structure and a low tolerance for ambiguity, and to be conservative, authoritarian, and racist in their sociocultural views" Beaumont (2008, pp 97)

Karen Stenner (2005) summarizes the foreclosed identity's characteristic urge to reduce complexity as:

"Intolerance to diversity = Authoritarianism $x$ normative fear level"

where authoritarianism is a measure of identity foreclosure. She describes normative threats as threats to oneness (shared authority) and sameness (shared values and rules).

"For authoritarians, then, the conditions most threatening to oneness and sameness [i.e., normative threats] are questioned or questionable authorities and values, for example, disrespect for leaders or leaders unworthy of respect, and lack of conformity with or consensus in group norms and beliefs" (Stenner 2009, pp. 143).

This is a good summary of the existential threat felt by foreclosures when their only strategy to secure well-being is frustrated. But when it is not threatened, foreclosures manifest intermediate levels of wellbeing (Berzonsky \& Cieciuch, 2016).

\section{Identity diffusion}

The fourth identity status is identity diffusion. It is characterized by avoided self-exploration in combination with a fluid or unstable self-identity. In our framework, this corresponds to both underdeveloped coping and co-creation. While aiming to improve their well-being, diffusives are often confronted with their own inadequacy. Intentions are good, realization is not. And one often ends up in, or even perpetuates, low viability states. And without self-exploration benefits, this cannot be understood or interpreted effectively. Much more than the other identity statuses, diffusives live in a random world of problems in which they cannot take responsibility for their actions. Which contrast to achievers who live is a world of opportunities to be explored and responsibly realized. Beaumont and Pratt (2011, pp 174) describes the associated identity style as:

\begin{abstract}
"A diffuse-avoidant identity style is associated with procrastination and attempts to evade identity conflicts and decisional situations as long as possible [all due to self-perceived inadequacy].... The use of a diffuse-avoidant style is characterized by low agreeableness, conscientiousness, introspectiveness, [complicating rule following] and cognitive complexity [indicating a shallow worldview], and high neuroticism. A diffuse-avoidant style is also associated with less adaptive cognitive and behavioral strategies, such as using avoidant coping strategies, engaging in taskirrelevant behaviors, expecting to fail, having a low feeling of mastery, and performing less strategic planning."
\end{abstract}

This description clearly demonstrates that diffusions exhibit a narrow range of marginally effective behavioral options that lock them in this status and curtail their well-being (Berzonsky \& Cieciuch, 2016). Nevertheless, self-development occurs and they can, later than others, adopt narrow effective strategies (towards the foreclosed identity status), develop self-exploration abilities (towards the moratorium status) or both (towards the achieved status).

\section{Psychology from core cognition}

We have demonstrated that core cognition can shed a fresh and productive light on identity development as an established concept in psychology. Identity development is related to the 
development of agency via a range of strategies to promote individual well-being constrained by coping and co-creation adequacy (or inadequacy). In the next section we expand the scope to social psychology and sociology.

\section{Section 4 - Two routes to general well-being}

This section addresses two routes to well-being. There are other routes to future well-being, in fact both the self-help literature as well as pretty much all modern ideologies propose routes to wellbeing. We have selected the 'ontological security' framework and a recent formulation of 'psychological safety' to represent very clear, actionable, and precisely worded coping and co-creation approaches to general well-being. In this section we will apply our core cognition framework as a metatheoretical perspective on the "theories" described below. This entails that we focus on the mindset, expressing either the coping or co-creation ontology, that originated the theories.

Ontological security and psychological safety refer to seemingly similar, but essentially different, concepts of the absence of danger that we address first.

\section{Safety versus Security}

Safety, as a situation or state with positive indicators of the absence of viability threats, is a precondition for co-creation and a precondition for achieving and maintaining the higher levels of well-being. Adequately co-creating agents self-organize a shared habitat while minimizing tension and conflict. Their co-creation adequacy prevents danger, harm or injury because it allows agents to focus on restoration and growth. In humans this is, for example, exemplified by the difference between calm and boring sonic environments that boils down to the presence or absence of audible safety (Andringa \& Lanser, 2013; Van den Bosch et al., 2013; van den Bosch et al., 2018). Also squirrels infer safety from bird chatter (Lilly, Lucore, \& Tarvin, 2019). In addition, recent studies to improve the well-being of people with dementia (where reduced higher cognition opens a window on more basic processing) show marked reduction in problem behavior by just reducing the prevalence of (unpleasant) sounds indicative of unsafety (Kosters, Koster, Andringa, Zuidema, \& Luijendijk, forthcoming).

While safety is a precondition for co-creation, security is the objective of coping. The Concise Oxford dictionary defines security as "the state of being free from danger or threat". Here we sharpen this definition to "a situation or state where viability threats-to-self have been brought under control", to stress its manifestation in coping. Socially, more prevalent coping corresponds to the changing role of the (national) security state from international war to policing domestic and foreign populations (Andreas, 2001; Raskin, 1976). Similarly organizations can both trust or distrust worker autonomy, when distrust is prevalent this leads to a high degree of coercive formalization of work (Adler and Borys, 1996; Andringa, 2015) These examples suggest that 'greater security' does not necessarily signify 'more safety.'

'Security' and 'safety' play central roles in the two attitudes towards the creation of well-being that we will discuss. Security provides actively maintained short term sanctuary by controlling threats to viability and through enhancing control of unmanageable diversity and complexity and is a manifestation of coping. Safety provides and creates environmental conditions conducive to long term well-being through avoiding problems, actively signaling the absence of threats, and an environment conducive for restoration, growth and, in general; co-creation.

\section{Ontological security}

\section{The Origins of Ontological Security}

Creating 'security' is associated with reducing fear by excluding "the unknown" and controlling whatever activates feelings of inadequacy. An in-group, as a defining feature, shares common adequacy limits and aims to control the environment to make it more orderly, stable, structured, and therefore, less threatening to the in-group by imposing limits on agency via routines, norms, and rules. This method of creating well-being is defined by theorists in Sociology and International Relations as 'ontological security' and we interpret it here as a perfectly formulated attempt by individuals in the coping mode to improve wellbeing. However, since it has the coping mode's limitations, it can only improve low well-being to a situation of no symptoms. It cannot bring about higher levels of well-being.

The concept of Ontological Security was popularized by Anthony Giddens, who described it as the secure feeling an individual derives from attaining "on the level of the unconscious and practical consciousness, 'answers' to fundamental existential questions [i.e., problems] which all human life in some way addresses" (1991, pp. 47). However, the origins of ontological security can be found in Laing's The Divided Self (1960). For Laing, psychoanalysis is about helping the patient reconstruct his identity or "way of being himself in his world" (Laing 2010, pp. 25) without showing overt symptoms. Laing states that individuals who have a "partial or almost complete absence" of this 'person-in-the-world' theory are more likely to develop psychosis and schizophrenia (2010, pp. 39). He describes:

"His identity and autonomy are always in question. He may lack the experience of his own temporal continuity. He may not possess an overriding sense of personal consistency or cohesiveness. He may feel more insubstantial than substantial, and unable to assume that the stuff he is made of is genuine, good, valuable" (Laing 2010, pp. 42).

Here, Laing is essentially describing the diffusive identity status; inadequate, unskilled, with an underdeveloped self-theory, and with an inadequate behavior repertoire that is often ineffective, and potentially, progressively disconnected from inner (self) and outer reality. He does not describe the other identity statuses because, as a mental health practitioner, his concern is with removing the symptoms of schizophrenia and psychosis, not with promoting optimal mental health, maximizing human potential or full self-actualization. Hence, the concept of ontological security emerges exclusively from the logic of the coping mode, as its formulation and conceptualization are ignorant of cocreation.

Giddens (1991) provides a sociological interpretation of Laing's insights arguing that our identity and autonomy, and by extension, our ontological security depends on our ability to trust in social narratives and routines in which we are contextually embedded and through which our identity is constituted. Adhering to norms and routines means individuals are not "obsessively preoccupied with their contingent, and fragile nature" (Rossdale 2017, pp. 371).

Gaining security for Giddens is not to "accept" reality and broaden and deepen adequacy by developing a richer self-theory through exploration of self and the world. Instead its purpose is "to create ontological reference points" which simplify reality so that inadequate agents can deal with "the contexts of day-to-day life" (1991, pp. 48) without learning and growth towards full selfactualization. In terms of figure 3 , the aim is to make the behavioral repertoire more effective, not broader. Hence it promotes both the normative identity style as well as authoritarianism. 


\section{Normative Threats to Ontological Security}

According to Gidden, norms and routines, which impose limits on behavior provide, us a "cognitive and emotional anchor" from which (inadequate) individuals derive the "trust" (Giddens 1991, pp. 36) that continuity and stability will prevail in everyday relations so that they are not confronted with their own inadequacy. Routines rely heavily on a complex range of shared knowledge: taken-for-granted local practices, cultural narratives, institutional structures, and 'common' knowledge (Berger and Luckmann 1991, pp. 35). In other words, the status quo is the 'anchor' security is derived from. Ontological security is associated with (normative) individuals who have a narrow but conditionally effective skill set for coping; they lack the behavioral repertoire breadth to deal with a world that is not under control of the in-group; and they feel an existential threat when so confronted.

This is a direct reference to Stenner's (2005) Authoritarian Dynamic that we addressed in section 3 on the foreclosed identity status that predicts authoritarianism. Individuals in a foreclosed status respond with intolerance to diversity when confronted with normative threats and hence they promote "common authority (oneness) and shared values (sameness). For authoritarians, then, the conditions most threatening to oneness and sameness [normative threats] are questioned or questionable authorities and values, for example, disrespect for leaders or leaders unworthy of respect, and lack of conformity with or consensus in group norms and beliefs" (Stenner 2009, pp. 143).

Here, the normative 'threat' to oneness and sameness concerns the condition of the self, more than of the perceived disturbance; "the self is unsure what to expect of the new: the exact boundary and inclusion or exclusion of the newcomer are not clear" (Chernobrov 2016, pp. 586). The unfamiliar 'new' exposes the agent's inadequacy; uncertainty regarding the unfamiliar "hamper [existing rules application and] calculation and increase risk, jeopardize perceived or actual security, or signal indeterminacy and lack of meaning" (Chernobrov 2016, pp. 582). Consequently, security is concerned with maintaining the relationship with the environment as it is. Inadequate agents are not equipped with skills to understand or deal with the unknown outside of ingroup controlled environments. (See Section 2 "Coping")

\section{Attempting Well-being via Ontological}

\section{Security}

The process of gaining ontological security is the process of becoming partially adequate via adoption of normative strategies (the status quo) to minimize viability threats. As Mitzen (2006, pp. 342) puts it "for theorists of ontological security, individual identity is formed and sustained through relationships" with significant others; a defining property of the foreclosed identity status and the associated normative identity style (Berzonsky, 2008) who expresses the coping mode structurally.

Berger and Luckmann (1991, pp. 71) refer to the adoption of routines and norms as 'habitualization'. Habitualization is the consolidation of routines via reference to socially constructed symbols, myths, and heritage - shared knowledge - that sustain an in-group identity, which, in the words of Kinvall, provides " $a$ guide for future actions" (2004, pp. 756). Norms, rules and routines impose group level limits on agency and reduce diversity, whilst increasing the probability of intended outcomes.

Individuals not only give meaning to their own normative experience, but are able to "unite [...] in a way that promotes order and predictability" (Gergen 2001, pp. 18 in Skey, 2010). The resulting less complex environment does no longer confront inadequate individuals with their inadequacy because it is, for them, more manageable and predictable, and it appears and appraises as less threatening. However, this complexity reduction also stipulates security is achieved via adherence to the status quo at the expense of personal freedom (authoritarianism) and options for self-guided contributions. Additionally, the façade of a less complex environment needs continual maintenance not to crumble in the face of reality. The weaker the façade appears, the stronger the normative threat and the more frantic the façade is defended and diversity suppressed.

As individuals/out-groups perceived as 'different' are almost always perceived as a threat, the out-group identity is constructed via othering (Skey, 2010; Kinvall, 2004; Rossdale, 2017). Inadequate co-creators are only familiar with and comfortable in their own in-group context so they will construct the unfamiliar individual's identity comparatively to one's own, with a focus on difference rather than similarity (Skey, 2010). This results in the construction of identities and routines as "relative to other identity constructions" (Kinvall 2004, pp. 762) making each in-group seemingly incompatible and inherently separate; viewing each other "as stereotyped members of a group relegated a foreign status" (Verkuyten 2005, pp. 131 in Skey 2013): out-groups.

Security is short term because it relies on effortful and continual control through the suppression of unwanted diversity (that exposes inadequacy limits). "The process of achieving (or seeking to achieve) ontological security frequently involves forms of exclusion and othering which may be both violent and counter-productive" (Rossdale 2016, pp. 370). As there is only coping, there is zero-gain; "increasing ontological security for one person or group [...] is thus likely to decrease security for those not included" (Kinvall 2004, pp. 763 ). Routines and rules are advantageous to the in-group, as they stipulate order and increased predictability, however, members of the out-group are disadvantaged by these rules and, in turn, are threatened and feel insecure. In-groups provide the out-group with grievances: exclusion, suppression, supervision, etc. which Silke (2008, pp. 112) asserts that if "marginalized groups are discriminated against or [...] believe that there is discrimination, then there will always be sections within such communities who will be receptive to radical ideologies" jeopardizing the security of the environment. "Empirically and normatively [ontological security] push[es] us in the wrong direction" (Nesbitt-Larking 2016, pp. 13).

Searching for security by relying on in-group norms and routine also can distract from real-world threats, and can actually make the group less safe and effective. When speaking of the failure of commercial organizations such as Radio Shack, Blockbuster or Kodak, Clark (2020) states: "These organizations were filled with large numbers of highly intelligent people, and yet they all fell prey to competitive threats that were hiding in plain sight. The countervailing strategies their competitors put in place were not mysterious. They were, in fact, obvious. What these organizations failed to do was challenge the status quo and disrupt themselves. [...] They allowed the status quo to fossilize and would not allow themselves to change it." In other words, protecting the status quo might not only fail to create a zero-net gain of well-being but might actually degrade it. This is the fate of existing exclusively under coping mode's limitations: it may prevent death, but it provides no guarantee for being well.

\section{Abnormal normality as the coping mode's ideal of well-being}

What does the ideal of ontological security look like? It will be a symptomless perfect adaptation to an effortfully maintained environment protected from everything that might freak out the foreclosed personality. Huxley (1958), quoting Fromm, noted that symptoms means conflict, which indicates

"that the forces of life which strive for integration and happiness are still fighting. The really hopeless victims of mental illness are to be found among those who appear to be most normal. 'Many of them are normal because they are so well adjusted to our mode of existence, because their human voice has been silenced so early in their lives, that they do not even struggle or suffer or develop symptoms as the neurotic does.' They are normal not in what may be called the absolute sense of the word; they are normal only in relation to a profoundly abnormal society. Their perfect adjustment to that abnormal society is a measure of their mental sickness. 
These millions of abnormally normal people, living without fuss in a society to which, if they were fully human beings, they ought not to be adjusted, still cherish "the illusion of individuality," but in fact they have been to a great extent de-individualized. Their conformity is developing into something like uniformity. But "uniformity and freedom are incompatible. Uniformity and mental health are incompatible too ... Man is not made to be an automaton, and if he becomes one, the basis for mental health is destroyed."

In the course of evolution nature has gone to endless trouble to see that every individual is unlike every other individual. We reproduce our kind by bringing the father's genes into contact with the mother's. These hereditary factors may be combined in an almost infinite number of ways. Physically and mentally, each one of us is unique. Any culture which, in the interests of efficiency or in the name of some political or religious dogma, seeks to standardize the human individual, commits an outrage against man's biological nature.

This dovetails with Maslow's observations about the suppression of an essential core, of which he says "even when its existence is denied, it never goes away, even in a sick person; and is constantly trying to get out. Discipline, deprivation, frustration, pain, and tragedy are necessary because these experiences foster and fulfill his inner nature." (Maslow 1968, pp. 3-4). Maslow argued that "psychologically speaking, that which designates a normal human being is in reality a psychopathology of the average. It depicts a lifestyle that is so widespread and nondramatic that we don't even notice it ordinarily. In general, this normal life is one of general phoniness, illusion, and fear; showing that it is a sickness that is widely spread." (1968, p. 16).

Striving for ontological security fosters then a psychopathology of the average: a state of marginal well-being and psychological emptiness that is the best that coping can produce. The question then is how to promote the highest levels of well-being.

\section{Psychological Safety}

Psychological safety is a term that was first derived in team work research where it helped to predict which teams worked well and which did not. Psychological safety promotes interpersonal risk taking (Edmondson, 1999) and signifies a change from a defensive and self-protective team role fulfillment to being a fully collaborating member without any motivation to self-protect.

Feeling safe is conditioned on positive indicators of safety. Safety is an outcome of successful previous behaviors (both coping and co-creation) and signifies that all is well. Therefore, safety signifies high adequacy, pervasive optimization (wisdom), inclusion, and $\mathrm{Wu}$ Wei. In such an environment changes are attended to before they become pressing problems, because in an inherently safe environment enough individuals have adequate skills to approach and adapt to the (natural dynamic of the) unfamiliar without feeling threatened and defensive.

Where ontological security has a focus on maximizing environmental mastery through minimizing habitat complexity, psychological safety has a focus on maximizing agentic contributions in ways that benefit the whole. Via anthropological fieldwork conducted on organizations "from every sector of society", Clark (2020) describes the concept as:

Psychological safety is a condition in which you feel (1) included, (2) safe to learn, (3) safe to contribute, and (4) safe to challenge the status quo-all without fear of being embarrassed, marginalized, or punished in some way.

Step four exemplifies interpersonal risk taking most clearly. Clark (2020) argues that the progression toward psychological safety is derived from the natural sequence of human needs; the preconditions required for co-creation to occur. Maslow's hierarchy of needs (1943) has 5 stages (physiological, security, belongingness, esteem, self-actualization) that correspond directly to Clark's progression towards psychological safety. The most basic needs for Maslow are physiological: food, water, shelter; which are the needs not included in Clark's psychological safety as it "is a postmaterialist need" (2020). Maslow's next three stages (security, belongingness, esteem) are the needs that Clark conceptualizes as the three needs from which psychological safety straddles. Psychological safety "is no less a human need than food or shelter" as it is the manifestation of the need for agentic selfpreservation, which has as much to do with social and emotional needs as physical ones" (Clark, 2020)." Once the basic needs of food, water, and shelter are met, psychological safety becomes a priority so its maximum potential is unleashed; self-actualization and co-creation preconditions are satisfied.

\section{Fours steps of psychological safety}

The first step for psychological safety is inclusion. The concept of inclusion underpins the difference between safety and security. When creating well-being via security, in-group membership is always conditional. In-group members feel unthreatened because of conditions which stipulate: sameness and oneness; security is derived from the suppression of diversity. When creating wellbeing via safety, membership to the community is "based on the sole qualification that they possess flesh and blood" (Clark, 2020).

For inclusion safety, agents must be equipped with the skills to negotiate the unfamiliar by extending both respect and permission. By respect, Clark means the average level of esteem agents afford to each other; how much agents value and appreciate the unfamiliar. By permission, Clark means that all are permitted to participate as members of the community; the degree to which the group allows the unfamiliar to influence them, and newcomers to participate. Permission and respect are important affordances that agents grant one another in order to create an environment that grants safe passage to learning in order to maximize agentic potential, cultivate confidence, resilience, and independence (Clark, 2020).

The next level of safety is learner safety. Learner safety implies you feel safe to participate, engage with the discovery process, ask questions, and make mistakes. The transition to learner safety means the agent faces the anxiety of the unknown (all signs of ingroupiness).

As individuals feel increasingly safe in a nurturing environment that offers respect and permission, we enter the stage of contributor safety. This is the stage the individual is invited to participate as a full-fledged member of the community and esteem needs are fulfilled (Maslow, 1943). The agent's contributions are successful; he gains self-esteem, whilst being adequate, and valuable, hence, he is respected by the community. Contributor safety emerges when the individual has acquired skills and is able to apply them adequately to produce shared benefits. The community has to provide both encouragement and appropriate autonomy to the agent (Clark, 2020). If the individual is hampered by discrimination, prevailing norms, internal bias, a lack of empathy, or general aloofness; the individual is denied contributor safety.

The final and crucial stage of psychological safety is challenger safety; an individual feels free to challenge the status quo without fear of retribution or reprisal (Clark, 2020). Challenger safety enables individuals to overcome the pressure to conform and, hence, can enlist themselves in co-creative processes; improvement, innovation, development and hence communal growth.

While allowing and promoting challenger safety is a defining feature of psychological safety, challenges to the status quo are exactly what is to be suppressed from an (ontological) security perspective. Here the in-groups focus on protecting and defending the rules, routines and norms that define the ingroup by suppressing diversity. Since ingroups feel inadequate under normative threats (challenges to sameness and oneness) any challenge is interpreted as an assault of precisely that what constitutes the normative and authoritarian identity. And that is the reason why it is incompatible with psychological safety. 
Psychological safety is achieved via maximizing member contributions so that (1) members are equipped with skills to confidently negotiate the unknown and (2) new members feel free to join, learn, contribute and criticize freely, and, therefore, never harbor motivations to threaten the well-being of the community. The result is a community or habitat presenting a high concentration of safety indicators in the form of unscripted contributions to the community. The progression towards psychological safety and fulfilling the natural sequence of human needs provides a recipe for co-creative well-being.

\section{Metatheoretical considerations}

The very formulation of the theory of ontological security shows that it is possible to formulate, with the best of intentions, a framework that is almost guaranteed to lead to a deeply pathological state of individual and societal non-development. Ideally this results in a situation of no symptoms with individuals perfectly adapted to a world that is kept within the limits of their underdeveloped co-creation adequacy. More realistically, it results in an unstable state because "increasing ontological security for one person or group [...] is thus likely to decrease security for those not included" (Kinvall 2004, pp. 763), which will bring in-groups inevitably outside of their scope of adequacy or well below their adequacy potential. Additionally, maintaining a world within any tight constraints is effortful and wasteful compared with societal skilling-up to deal with full real-world complexity, as threats and opportunities, as effective co-creation affords.

Although this might be convincing arguments for some, it is not an argument for in-groups (i.e., authoritarians), especially not for those under normative stress, who simply assume that outgroups will either comply with in-group rules or be dealt with otherwise (eliminated or made irrelevant). Due to the absence of self-exploration and the associated broadening of the behavioral repertoire towards co-creation adequacy, this entails that the coping worldview is simply not rich enough to adequately assess its own limitations, let alone understand full human potential. Possibly this also characterizes the formulators of ontological security, which is all the more likely since they seem unaware of the existence of co-creation.

The formulation of psychological security expresses co-creation very clearly, but it is concurrently aware of coping and its limitations because it straddles across co-creation and coping skills. So, the ability to do be adequate at both differentiates the moratorium (and the foreclosed) identity status from the achieved identity.

Clark's (2020) description of the preconditions for psychological safety in combination with the internal logic of the ontological security framework inspired us to produce a metatheoretical summary, in Figure 3, that builds on Maslow's pyramid of needs (1943). The key transition in this well-being pyramid occurs between the lower level and access to self-directed growth towards self-actualization. The transition occurs when coping strategies stop being dominant and co-creation takes over with coping as a valuable fallback to address pressing problems quickly. This corresponds to a change from in-groups that conditionally accept individuals - namely if and only if they accept the in-group worldview and, hence, direct and curtail their behaviors according to shared adequacy limits - to a community that unconditionally accepts individuals and allows them to learn, contribute, and criticize. This makes the group diverse in its ability to solve problems and realize opportunities and it offers ample context for individual and community growth.

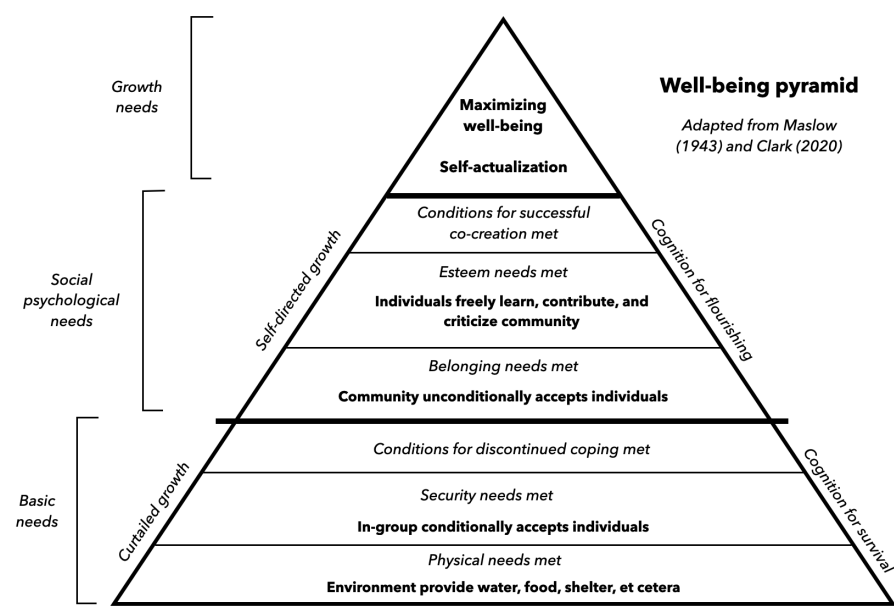

Figure 3: Well-being pyramid. The key transition is from conditional acceptance by ingroups to unconditional acceptance by a (diverse) community.

\section{Section 5 - Reflection}

In this (long) paper we aimed to derive central aspects of cognition from first principles that we call core cognition. We summarized many of its key terms in Table 1. We derived two separate forms of cognition; coping: for addressing pressing problems and, hence, aimed at its termination; and co-creation: aimed at optimizing everything in the context of everything else and aimed at it perpetuation. We claim that while both strategies are essential; it is the interplay of their strengths that, somewhat unexpectedly but logically, leads to the dominance of one of them: co-creation. Because we derive our conclusions from studying generic living agents, we claim that our results not only pertain to human well-being, but to well-being in general: wellbeing for all living beings and by extension for the biosphere.

The different purpose and character of coping and co-creation leads to two complementary ontologies of cognition that each follow their own internal logic and have separate key concepts. Coping expresses the cognition for survival and co-creation expresses cognition for flourishing. The differences in goals and internal logic of coping and co-creation entails that individuals who approach the world from different logics do not understand each other at all. Coping and co-creation adequacy has to be learned from real-world interactions on top of innate abilities (to acquire these).

Section 3 showed that the four combinations of coping and cocreation adequacy or inadequacy underlie the structure of identity in humans and shed a new light on why the identity statuses have their characteristic properties and how this connects to how each status approaches information.

In Section 4 we applied core cognition as a meta-theoretic tool. We concluded that striving to realize what is known in the literature as 'ontological security' is a precise expression of the coping mode's (limited) capacity for well-being. In fact, we concluded that ontological security leads to a self-limiting form of well-being that has been described as abnormal normality by Huxley (1958) and Fromm and as "the pathology of the average" by Maslow 1968, p. 16). In contrast Maslow's understanding of wellbeing and self-actualization exemplifies co-creation. And we concluded that psychological safety provides the only preconditions that maximize well-being and the healthy development of coping and co-creation adequacy.

Already in 1973 Newell wondered about Psychology's ability to produce wonderful scientific papers (Newell, 1973). He asked himself the question whether Psychology would have achieved "a science of man" at his retirement age (in 1992), or would another 
multi-decade period of paper production be necessary to "home in on the essential structure of the mind." Perhaps we have contributed a framework that helps make sense of the huge body of data that psychology has compiled. We hope we have and we will investigate this further by applying core cognition insights in diverse domains such as happiness and education research, separate brain systems such as dual type processing (Evans and Stanovich, 2013) the left \& right hemisphere (McGilChrist, 2012), and the structure of values (Fontaine et al., 2008). Our hope is not to fragment knowledge and understanding any further, but to find ways in which to unify the acquired body of evidence in a more manageable framework. 


\section{References}

Adler, P. S., \& Borys, B. (1996). Two types of bureaucracy: Enabling and coercive. Administrative Science Quarterly, 41(1), 61-89.

Andringa, T. C., \& Angyal, N. (2019). The nature of wisdom: people's connection to nature reflects a deep understanding of life. Psychology. Journal of the Higher School of Economics, 16(1), 108-126. http:/ / doi.org/10.17323/1813-8918-2019-1-108-126

Andringa, T. C., \& Lanser, J. J. (2013). How Pleasant Sounds Promote and Annoying Sounds Impede Health: A Cognitive Approach. International Journal of Environmental Research and Public Health, 10(4), 1439-1461.

http: / / doi.org/10.3390/ijerph10041439

Andringa, T. C., van den Bosch, K. A. M., \& Wijermans, N. (2015). Cognition from life: the two modes of cognition that underlie moral behavior. Frontiers in Psychology, 6(362), 1-18. http: / / doi.org/10.3389/fpsyg.2015.00362

Andringa, T. C. (2015). The Psychological Drivers of Bureaucracy: Protecting the Societal Goals of an Organization. In Policy practice and digital science: integrating complex systems, social simulation and public administration in policy research (First, pp. 221-260). Cham: Springer International Publishing. http:/ / doi.org/10.1007/978-3-319-12784-2 11

Barandiaran, X., Di Paolo, E. A., and Rohde, M. (2009). Defining agency: individu- ality, normativity, asymmetry, and spatiotemporality in action. Adapt. Behav. 17, 367-386. http: / / doi: $10.1177 / 1059712309343819$

Beaumont, S. L. (2009). Identity Processing and Personal Wisdom: An Information-Oriented Identity Style Predicts SelfActualization and Self-Transcendence. Identity, 9(2), 95-115. http: / / doi.org/10.1080/15283480802669101

Beaumont, S. L., \& Pratt, M. M. (2011). Identity Processing Styles and Psychosocial Balance during Early and Middle

Adulthood: The Role of Identity in Intimacy and Generativity. Journal of Adult Development, 18(4), 172-183. http: / / doi.org/10.1007/s10804-011-9125-z

Berzonsky, M. D. (1989). The self as a theorist: Individual differences in identity formation. International Journal of Personal Construct Psychology, 2(4), 363-376. http: / / doi.org/10.1080/08936038908404746

Berzonsky, M. D. (2008). Identity formation: The role of identity processing style and cognitive processes. Personality and Individual Differences, 44(3), 645-655.

http:/ / doi.org/10.1016/j.paid.2007.09.024

Berzonsky, M. D., \& Cieciuch, J. (2016). Mediational role of identity commitment in relationships between identity processing style and psychological well-being. Psychmetrika, 17(1), 145-162. http://doi.org/10.1007/ s10902-014-9588-2

Berger, P. and T. Luckmann. (1991) The Social Construction of Reality: A Treatise in the Sociology of Knowledge,

Harmondsworth: Penguin

Brindley, E. (2010). Individualism in early China. Retrieved August 29, 2013, from

http: / / search.ebscohost.com/login.aspx?direct=true\&scope $=S$ ite $\& \mathrm{db}=$ nlebk\&db=nlabk\&AN $=336258$

Clark, T. R. (2020). The 4 stages of psychological safety: defining the path to inclusion and innovation. Berrett-Koehler Publishers.

Combs, A., \& Kribner, S. (2008). Collective Consciousness and the Social Brain. Journal of Consciousness Studies, 15(10-11), 264276.

Di Paolo, E. A. (2009). Extended life. Topoi, 28, 9-21.

Di Paolo, E. A., and Thompson, E. (2014). "The enactive approach," in The Routledge Handbook of Embodied Cognition, ed. L. Shapiro (London: Routledge Press), 1-14.

Doyle, M. J., \& Marsh, L. (2013). Stigmergy 3.0: From ants to economies. Cognitive Systems Research, 21, 1-6. http: / / doi.org/10.1016/i.cogsys.2012.06.001

Edmondson, A. (1999). Psychological Safety and Learning Behavior in Work Teams. Administrative Science Quarterly, 44(2), 350-383. http: / / doi.org/10.2307/2666999

Evans, J. S. B. T., \& Stanovich, K. E. (2013). Dual-Process Theories of Higher Cognition Advancing the Debate.
Perspectives on Psychological Science, 8(3), 223-241.

http: / / doi.org/10.1177/1745691612460685

Fontaine, J. R. J., Poortinga, Y. H., Delbeke, L., \& Schwartz, S. H. (2008). Structural Equivalence of the Values Domain Across Cultures: Distinguishing Sampling Fluctuations From Meaningful Variation. Journal of Cross-Cultural Psychology, 39(4), 345-365. http: / / doi.org/10.1177/0022022108318112

Fredrickson, B. L., \& Branigan, C. (2005). Positive emotions broaden the scope of attention and thought-action repertoires. Cognition \& Emotion, 19(3), 313-332. http: / / doi.org/10.1080/02699930441000238

Froese, T., \& Ziemke, T. (2009). Enactive artificial intelligence: Investigating the systemic organization of life and mind. Artificial Intelligence, 173(3-4), 466-500.

Gibson, J. (1979). The theory of Affordances. Chapter 8 of the Ecological Approach to Visual Perception, Lawrence Erlbaum Associates, New Jersey, 127-144.

Giddens, A. (1991). Modernity and self-identity: Self and society in the late modern age. Stanford university press.

Gloag, E. S., Javed, M. A., Wang, H., Gee, M. L., Wade, S. A., Turnbull, L., \& Whitchurch, C. B. (2013). Stigmergy: A key driver of self-organization in bacterial biofilms. Communicative $\mathcal{E}$ Integrative Biology, 6(6), e27331-11546. http: / / doi.org/10.4161/cib.27331

Heylighen, F. (2016a). Stigmergy as a universal coordination mechanism I: Definition and components. Cognitive Systems Research, 38, 4-13. http:/ / doi.org/10.1016/i.cogsys.2015.12.002

Heylighen, F. (2016b). Stigmergy as a universal coordination mechanism II: Varieties and evolution. Cognitive Systems Research, 38, 50-59. http: / / doi.org/10.1016/j.cogsys.2015.12.007

Hofmann, E., Hartl, B., Gangl, K., Hartner-Tiefenthaler, M., \& Kirchler, E. (2017). Authorities' Coercive and Legitimate Power: The Impact on Cognitions Underlying Cooperation. Frontiers in Psychology, 8, 224-15. http: / / doi.org/10.3389/fpsyg.2017.00005

Huxley, A. (1958). Brave new world revisited. (1st ed.). New York: Harper.

Kinnvall, C. (2004). Globalization and religious nationalism: Self, identity, and the search for ontological security. Political psychology, 25(5), 741-767.

Kosters, J., Koster, Andringa, T. C., Zuidema, S. U., \& Luijendijk, H. J. (in preparation). Soundscape improvement with MoSART + to reduce neuropsychiatric symptoms in nursing home residents with dementia: a cluster-randomized controlled trial.

Kuppens, P., Champagne, D., \& Tuerlinckx, F. (2012). The dynamic interplay between appraisal and core affect in daily life. Frontiers in Psychology, 3, 1-8. http: / / doi.org/10.3389/fpsyg.2012.00380

Laing, R. D. (2010). The Divided Self, London: Penguin

Lilly, M. V., Lucore, E. C., \& Tarvin, K. A. (2019). Eavesdropping grey squirrels infer safety from bird chatter. PLoS One Computational Biology, 14(9), 15. http: / / doi.org/10.1371/journal.pone.0221279

Littlejohn, R. (2003). Daoist Philosophy. Retrieved August 2013, from http: / / www.iep.utm.edu/daoism/

Marcia, J. E. (1966). Development and validation of ego-identity status. Journal of Personality and Social Psychology, 3(5), 551-558. http: / / doi.org/10.1037/h0023281

Marcia, J. E. (1967). Ego identity status: relationship to change in self-esteem, "general maladjustment," and authoritarianism1. Journal of Personality, 35(1), 118-133. http: / / doi.org/10.1111/j.1467-6494.1967.tb01419.x

Marsh, L., \& Onof, C. (2008). Stigmergic epistemology, stigmergic cognition. Cognitive Systems Research, 9(1-2), 136149. http:/ / doi.org/10.1016/j.cogsys.2007.06.009

Maslow, A. H. (1943). A theory of human motivation. Psychological review, 50(4), 370-396.

Maslow, A. H. (1962). Notes on Being-Psychology. Journal of Humanistic Psychology, 2(2), 47-71.

Maslow, A. H. (1968). Toward A Psychology of Being. New York: D. van Nostrand company inc. 
McGilchrist, I. (2012). The Divided Brain and the Search for Meaning. Yale University Press.

Mitzen, J. (2006). "Ontological Security in World Politics: State Identity and the Security Dilemma." European Journal of International Relations 12(3): 341-70.

Nesbitt-Larking, P. (2016). "We Got To Live Together": The Psychology of Encounter and the Politics of Engagement. Political Psychology, 37(1), 5-16.

Newell, A. (1973). You can't play 20 questions with nature and win: Projective comments on the papers of this symposium. In W. G. Chasé (Ed.), Visual information processing (pp. 283-308). New York: Academic Press.

Noble, G. (2005). The discomfort of strangers: Racism, incivility and ontological security in a relaxed and comfortable nation. Journal of intercultural studies, 26(1-2), 107-120.

Prigogine I., Lefever R. (1973) Theory of Dissipative Structures. In: Haken H. (eds) Synergetics. Vieweg+Teubner Verlag, Wiesbaden. https: / / doi.org/10.1007/978-3-663-01511-6 10

Raskin, M. G. (1976). Democracy versus the National Security State. Law and Contemporary Problems, 40(3), 189. http: / / doi.org/10.2307/1191397

Rossdale, Chris (2015) Enclosing critique: the limits of ontological security. International Political Sociology, 9 (4). 369386

Russell, J. (2003). Core Affect and the Psychological Construction of Emotion, Psychological Review 110(1), 145-172.

Russell, B. (1938). Power (1st ed.). London: George Allen \& Unwin.

Ryan, R. M., \& Connell, J. P. (1989). Perceived locus of causality and internalization: Examining reasons for acting in two domains. Journal of Personnel Psychology, 57(5), 749-761. http: / / doi.org/10.1037/0022-3514.57.5.749

Silke, A. (2008). Holy warriors: Exploring the psychological processes of jihadi radicalization. European journal of criminology, 5(1), 99-123.

Skey, M. (2010). 'A sense of where you belong in the world': National belonging, ontological security and the status of the ethnic majority in England. Nations and Nationalism, 16(4), 715733.

Skey, M. (2013). Why do nations matter? The struggle for belonging and security in an uncertain world. The British journal of sociology, 64(1), 81-98.

Stenner, K. (2005). The authoritarian dynamic (First Edition). New York: Cambridge University Press.

Stenner, K. (2009). Three kinds of "conservatism". Psychological Inquiry, 20(2-3), 142-159.

Sternberg, R. (1998). A balance theory of wisdom. Review of General Psychology, 2(4), 347-365.

van den Bosch, K. A. M., Andringa, T. C., \& Vlaskamp, C. (2013). The role of sound and audible safety in special needs care (pp. 1-6). Presented at Internoise 2013.

van den Bosch, K. A. M., Welch, D., \& Andringa, T. C. (2018). The Evolution of Soundscape Appraisal Through Enactive Cognition. Frontiers in Psychology, 9, 1-11. http:/ / doi.org/10.3389/fpsyg.2018.01129

Vernon, D. (2010). Enaction as a conceptual framework for developmental cognitive robotics. Paladyn, 1(2), 89-98. http:/ / doi.org/10.2478/ s13230-010-0016-y

Walker, B., Holling, C. S., Carpenter, S. R., \& Kinzig, A. (2004). Resilience, adaptability and transformability in social-ecological systems. Ecology \& Society, 9(2), 5. 